\title{
Research
}

Sheena Mc Hugh, Claire Buckley, Katie Murphy, Sue Doherty, Gabrielle O’Keeffe, Joseph Alade, Elizabeth Keane, Mark James, Ciaran Coughlan, John Traynor, Colin P Bradley, Ivan J Perry, Joe Moran and Diarmuid Quinlan

\section{Quality-assured screening for diabetic retinopathy delivered in primary care in Ireland:}

\author{
an observational study
}

\begin{abstract}
\section{Background}

At present, there is no national population-based retinopathy screening programme for people in Ireland who have diabetes, such as those operating in the UK for over a decade.

\section{Aim}

To evaluate a community-based initiative that utilised existing resources in general practice and community optometry/ophthalmology services to provide screening for diabetic retinopathy.

\section{Design and setting}

Cross-sectional study using electronic ophthalmic patient screening records in community optometry clinics in Cork, Ireland.

\section{Method}

A purposive sample of 32 practices was recruited from Diabetes in General Practice, a general practice-led initiative in the South of Ireland. Practices invited all adult patients registered with diabetes to participate in free retinopathy screening $(n=3598)$, provided by 15 community optometry practices and two community ophthalmologists. Data were recorded on an electronic database used by optometrists and the performance was benchmarked against proposed national

Diabetes places a significant burden on the health system, which is largely attributable to the cost of managing and treating complications. 1,2 Diabetic retinopathy, a microvascular complication, is a condition that is preventable for the most part with optimal medical management. Early detection through retinopathy screening enables timely treatment in the event of diabetic eye disease developing. ${ }^{3}$ Nevertheless, diabetic retinopathy is one of the most common causes of visual impairment in the adult population. ${ }^{4-6}$ In Ireland, the incidence of blindness among people with diabetes is not known. However, a study conducted in 2003 using data from the National Council of the Blind found an increase of $120 \%$ in the numbers registered as blind as a result of diabetic retinopathy, between $1996(n=147)$ and $2003(n=323)$, which is an increase from 5.2 per 100000 adults in 1996 to 10.7 per 100000 adults in 2003.
\end{abstract} standards for retinopathy screening.

\section{Results}

In total, 30 practices participated (94\%). After 6 months, $49 \%$ of patients ( $n=1763$ ) had been screened, following one invitation letter and no reminder. Forty-three per cent of those invited consented to their data being used in the study and subsequent analyses are based on that sample ( $n=1542$ ). The mean age of the patients screened was 65 years ( standard deviation $=13.0$ years), $57 \%$ were male ( $n=884$ ), and $86 \%$ had type 2 diabetes $(n=1320)$. In total, $26 \%$ had som level of retinopathy detected ( $n=395)$; $21 \%$ had background retinopathy ( $n=331), 3 \%$ had preproliferative retinopathy ( $n=53)$, and $0.7 \%$ had proliferative retinopathy $(n=11)$.

\section{Conclusion}

The detection of retinopathy among $26 \%$ of those screened highlights the need for a national retinopathy screening programme in Ireland. Significant learning, derived from the implementation of this initiative, will inform the national programme

\section{Keywords}

diabetic retinopathy; general practice; optometry: quality assurance; primary care; screening.

\section{INTRODUCTION}

Routine retinopathy screening is an internationally accepted standard of diabetes care, $^{8-10}$ and the provision of population-based screening has been prioritised by national ${ }^{11}$ and international policymakers. ${ }^{12,13}$ At present, there is no national level population-based retinopathy

S Mc Hugh, PhD, post-doctoral researcher J Alade, MPH, research assistant; IJ Perry FRCP, FRCPI, MFPHM, MFPHMI, professor of public health \& epidemiology, Department of Epidemiology and Public Health, University College Cork, Ireland. C Buckley, GP; K Murphy, diabetes nurse facilitator with DiGP: G O'Keefe, HSE general manager, South Cork PCC; E Keane HSE director of public health, HSE Cork/Kerry; M James, community ophthalmologist, Mid-West Diabetes Retinopathy Screening Service; C Coughlan, IT HSE Primary Care Unit; J Traynor community medical ophthalmologist, Diabetes Services Implementation Group (DSIG) Cork and Kerry Retinopathy Subgroup, Health Service Executive. S Doherty, optometrist, Association of Optometrists Ireland (AOI). CP Bradley, professor screening programme for people in Ireland who have diabetes. A number of the challenges outlined by Younis et al in relation to retinopathy screening in the UK over a decade ago, ${ }^{14}$ are pertinent in Ireland today, including patchy provision, undocumented efficacy, and a lack of quality assurance. Diabetic retinopathy screening services in Ireland have described the level of service as 'ad-hoc', with a lack of consistency in screening methodologies. ${ }^{11}$ While most GPs have access to ophthalmic examination for their patients with diabetes, the service is provided by a variety of professionals, including ophthalmic surgeons, community ophthalmologists, and optometrists. ${ }^{1}$

The provision of a national retinopathy screening service was prioritised by the National Clinical Care Programme for Diabetes in 2009. In the absence of this service, a community-based initiative was established in 2010 , to provide accessible quality-assured screening to people with diabetes in Cork, Ireland. The initiative was delivered through practices involved in Diabetes in General Practice (DiGP), a GP-led forum that aims to improve the quality of diabetes care through continuing professional development, audit, and education. The screening initiative also utilised existing resources in the community, through engagement with local optometry

of general practice, GP; J Moran, GP; D Quinlan, GP. Diabetes in General Practice (DiGP) Ltd, University College Cork, Cork, Ireland.

\section{Address for correspondence}

Sheena Mc Hugh, Department of Epidemiology and Public Health, Western Gateway Complex, University College Cork, Western Road, Cork, Ireland.

E-mail: s.mchughهucc.ie

Submitted: 10 May 2012; Editor's response: 10 July 2012; final acceptance: 31 August 2012. @British Journal of General Practice

This is the full-length article (published online 28 Jan 2013) of an abridged version published in print. Cite this article as: $\mathbf{B r} \mathbf{J}$ Gen Pract 2013. DOI: 10.3399/bjgp13X663091 


\section{How this fits in}

Diabetic retinopathy is a serious but largely preventable complication. Communitybased retinopathy screening, which utilises existing resources and expertise, is a viable model of routine screening and is a practical example of multidisciplinary quality-assured chronic disease management in the primary care setting

and ophthalmology services. The aim of this study was to evaluate the performance of the initiative against the proposed national quality-assurance standards for retinopathy screening. ${ }^{11}$ Specifically, the study sought to examine the feasibility of delivering community-based retinopathy screening using local optometry and ophthalmology services, to assess the response rate to an invitation for eye screening issued from general practice, to assess the prevalence of the different classifications of diabetic retinopathy in a screened population in Ireland, and, finally, to identify potential challenges and opportunities to inform the implementation of a national screening service in Ireland.

\section{METHOD}

\section{Design and setting}

All practices participating in the DiGP group were invited to take part in the screening initiative ( $n=32)$. Practices were responsible for inviting all registered patients laged $\geq 18$ years) diagnosed with diabetes (type 1 or type 2) to attend for free eye screening. The invited population included those who may have been recently screened

Figure 1. Patient care pathway adapted from the proposed national framework. ${ }^{11}$ elsewhere ffor example, hospital screening service). Patients who were already blind, did not have perception of light in either eye, or had pre-diabetes, were excluded. Those deemed by their GP to be medically unfit to attend screening were also excluded.

Fifteen community optometry clinics provided screening in their own premises and were required to have access to a Procurement and Supply Authority (PASA)approved camera to participate. Two community ophthalmologists screened patients with ungradable images. Five of the participating optometrists were also responsible for grading images and had completed a diabetic retinopathy grading course recognised by the Association of Optometrists Ireland.

\section{Retinal screening}

Optometrists utilised a two-field Fundus $45^{\circ}$ digital PASA-approved camera for screening. Following dilation of the patient's pupil, digital retinal photographs of two nominal $45^{\circ}$ fields per eye were taken (macular and disc fields), consistent with the Europe and Diabetes study (EURODIAB) protocol. ${ }^{16}$ Images were reviewed by the optometrist for quality and, where necessary, another image was taken. Patients with poor-quality images because of technical failures were recalled to the optometry clinic, usually within 2 weeks, for re-screening.

\section{Data collection}

Data were collected from 1 January until 30 June 2011. Patients were allocated a unique identifier to enable secure transfer of data without risk of identification. Optometrists uploaded images to processing software provided by Medical Diagnostic and Treatment Solutions Ltd (MDTS). The grader then viewed each image uploaded onto the MDTS database, using digital photographic standards to check for retinal abnormalities. As a quality-assurance mechanism, $100 \%$ of images were also graded by a secondary grader (optometrist) and any discrepancies were sent for arbitrary grading by an ophthalmologist. All results were recorded on an electronic ophthalmic screening record and sent to the individual's GP within 2 weeks of screening. The GP was then responsible for referring patients for treatment where necessary. The patient care pathways were adopted from the National Framework for a Diabetic Retinopathy Screening Programme in Ireland (Figure 1)..11

The anonymised data collated by the MDTS software were supplemented with 


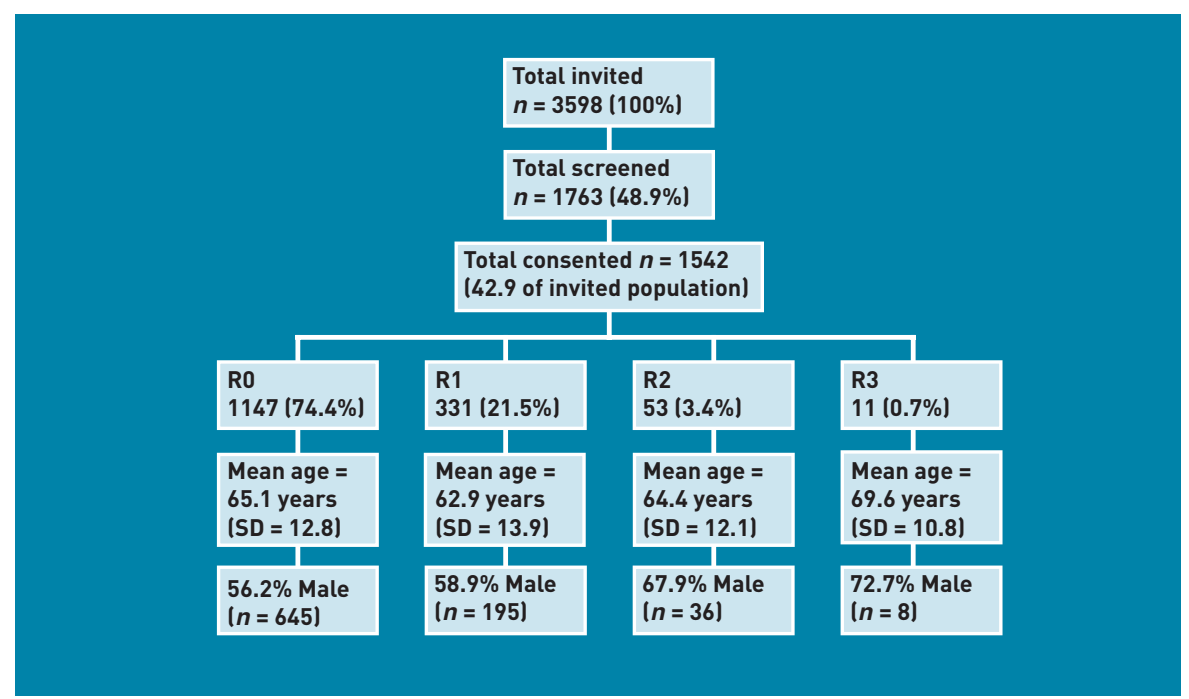

Figure 2. Percentage of sample invited, screened, and consented, and the level of retinopathy detected. $S D=$ standard deviation.

Figure 3. Consultation waiting times for the newly referred patients requiring a consultation within 13 weeks ( $=53$ ), based on hospital data.

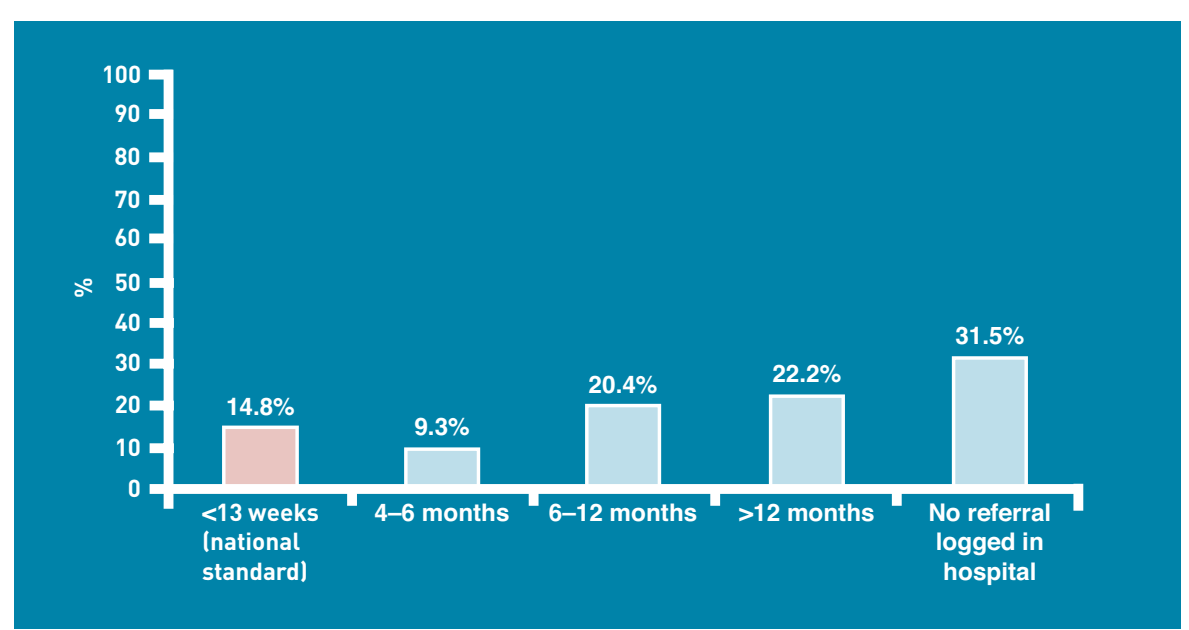

\section{Statistical analysis}

Analysis was performed using Statistical Product and Service Solutions software; SPSS (PASW) for Windows, (version 18.0). Categorical data are presented as numbers, proportions, and $95 \%$ confidence intervals (Cls). Continuous data are presented as mean \pm standard deviation (SD).

\section{RESULTS}

Thirty practices took part in the initiative (94\%). All eligible patients attending the practices were invited for screening $(n=3598)$. At the time of analysis, 6 months after commencement, $48.9 \%$ of patients had been screened ( $n=1763$ ) following one invitation letter and no reminder. The uptake rate in practices ranged from $18 \%(n=17)$ to $67 \%(n=45)$. Excluding those who did not consent to be included in the evaluation, data were available for 1542 patients (43\% of the population initially invited) (Figure 2). Of those who consented to the evaluation, $42.7 \%$ were female $(n=658) ; 57.3 \%$ were male ( $n=884) ; 85.6 \%(n=1320)$ had type 2 diabetes and $4.9 \%(n=76)$ had type 1 diabetes. The mean age of patients was 65 years $(S D=13.0$ years) (males $=64$ years, females $=65$ years).

Overall, 395 patients had some level of retinopathy detected during screening $(25.6 \%, 95 \% \mathrm{Cl}=23.5 \%$ to $27.9 \%)$. Of the 395 patients with retinopathy detected (R1, R2, R3), 239 (60.5\%) were male (60.5\%) and 156 were female (39.5\%). Most patients with retinopathy had type 2 diabetes (78\%, $n=308)$ and were in the 61-70 years age category (30.9\%, $n=122)$. There were 331 patients with background retinopathy (R1) $(21.5 \%, 95 \% \mathrm{Cl}=19.5 \%$ to $23.6 \%), 53$ patients had pre-proliferative retinopathy (R2) (3.4\%, $95 \% \mathrm{Cl}=2.6 \%$ to $4.5 \%$ ), and 11 patients had proliferative (sight-threatening) retinopathy (R3) $(0.7 \%, 95 \% \mathrm{Cl}=0.4 \%$ to $1.3 \%)$ (Figure 2). Of those with proliferative retinopathy, most patients were male $(72.7 \%, n=8)$, in the $71-80$ years age category $(54.5 \%, n=6)$, and had type 2 diabetes $(72.7 \%, n=8)$.

Sixty-eight patients had clinically significant diabetic maculopathy (M1) detected (4.4\%). Of those patients, 37 also had background retinopathy (M1 and R1) (54.4\%), 24 had pre-proliferative retinopathy (M1 and R2) (35.3\%), and seven had proliferative retinopathy (M1and R3) (10.3\%).

All 11 patients with proliferative retinopathy (R3) were referred to the ophthalmology service within 1 week of results being posted to the GP. Eight patients were referred to the public outpatient hospital service and three were referred to services privately. Seven of the 


\section{Table 1. Benchmarking performance of the initiative against the proposed national standards $\mathbf{s}^{11}$}

\begin{tabular}{|c|c|c|c|}
\hline Objective & Criteria & Minimum standard & Standard achieved \\
\hline $\begin{array}{l}\text { To invite all eligible persons with known diabetes } \\
\text { to attend for the diabetic retinopathy } \\
\text { screening test }\end{array}$ & $\begin{array}{l}\text { - Proportion of GPs participating } \\
\text { - Proportion of known people with } \\
\text { diabetes on the register } \\
\text { - Percentage of eligible people with } \\
\text { diabetes invited } \\
\text { - Single collated list of all people } \\
\text { with diabetes } \\
\text { - Systematic call/recall from a } \\
\text { single centre of all people eligible } \\
\text { for screening }\end{array}$ & $\begin{array}{l}90 \% \\
90 \% \\
100 \%\end{array}$ & $\begin{array}{l}94 \% \\
100 \% \\
100 \% \\
\text { No single register } \\
\text { Not applicable (first screening) }\end{array}$ \\
\hline $\begin{array}{l}\text { To maximise the number of invited persons } \\
\text { accepting the test }\end{array}$ & $\begin{array}{l}\text { Percentage of eligible persons } \\
\text { accepting the test: } \\
\text { 1. Initial screen } \\
\text { 2. Repeat screening }\end{array}$ & $70 \%$ & $\begin{array}{l}49 \% \\
\text { Not applicable (first test) }\end{array}$ \\
\hline To ensure photographs are of adequate quality & $\begin{array}{l}\text { Percentage of ungradable } \\
\text { patients in at least one eye }\end{array}$ & Raw ungradable, $U<10 \%$ & $6 \%$ \\
\hline To ensure grading is accurate & $\begin{array}{l}\text { Inter- and intra-grader agreement: } \\
\text { 1. for referable images } \\
\text { 2. for non-referable images } \\
\text { 3. for ungradable images }\end{array}$ & $\begin{array}{l}\text { Programmes must provide } \\
\text { evidence of internal quality- } \\
\text { assurance activity in annual } \\
\text { reports }\end{array}$ & $\begin{array}{l}\text { All images were graded by a } \\
\text { secondary grader. Any discrepancy } \\
\text { between primary and secondary } \\
\text { graders was sent for arbitrary } \\
\text { grading }-30 \% \text { of images were } \\
\text { sent for arbitrary grading ( } n=462 \text { ) }\end{array}$ \\
\hline $\begin{array}{l}\text { To ensure optimum workload for graders, } \\
\text { to maintain expertise }\end{array}$ & Optometrists/ophthalmologists & $\begin{array}{l}\text { Each optometrist or } \\
\text { ophthalmologist should grade a } \\
\text { minimum of } 500 \text { patient image } \\
\text { sets per annum }\end{array}$ & $\begin{array}{l}\text { Four graders out of five graders } \\
\text { graded more than } 500 \text { images; the } \\
\text { fifth grader graded } 432 \text { images }\end{array}$ \\
\hline $\begin{array}{l}\text { To ensure timely referral of patients with R3 } \\
\text { (fast track) screening results (emailed or faxed) }\end{array}$ & $\begin{array}{l}\text { Time between screening encounter } \\
\text { and issue of referral request: } \\
\text { flagged by screener/grader as R3 } \\
\text { fast-track referral, where } \\
\text { secondary grading and appropriate } \\
\text { referral action within } 1 \text { week is } \\
\text { required }\end{array}$ & $\begin{array}{l}100 \% \text { seen within } \\
2 \text { calendar weeks }\end{array}$ & $\begin{array}{l}100 \% \text { of } \mathrm{R} 3 \text { patients referred by the } \\
\text { GP within } 1 \text { week of receiving the } \\
\text { results report; one patient received } \\
\text { a consultation within the } 2 \text {-week } \\
\text { target at the time of evaluation }\end{array}$ \\
\hline $\begin{array}{l}\text { To ensure the GP and patient are informed of } \\
\text { all test results }\end{array}$ & $\begin{array}{l}\text { Time between screening encounter } \\
\text { and issuing of result letters to GP } \\
\text { and patient }\end{array}$ & $70 \%<3$ weeks; $100 \%<6$ weeks & $\begin{array}{l}100 \%<3 \text { weeks; } 100 \%<6 \text { weeks; } \\
\text { patients were advised to contact } \\
\text { their GP for the result }\end{array}$ \\
\hline $\begin{array}{l}\text { To ensure the public and healthcare professionals } \\
\text { are informed of performance of the screening } \\
\text { programme at regular intervals }\end{array}$ & Production of annual report & & Produced an evaluation report \\
\hline $\begin{array}{l}\text { To optimise programme efficiency and ensure } \\
\text { ability to assure quality of service }\end{array}$ & Minimum programme size & $\begin{array}{l}\text { Population including } 12000 \\
\text { people diagnosed with diabetes } \\
\text { on current patient list }\end{array}$ & $\begin{array}{l}\text { Population size of } 3598 \text { in one Health } \\
\text { Service Executive area }\end{array}$ \\
\hline $\begin{array}{l}\text { To ensure that screening and grading of retinal } \\
\text { images are provided by a trained and competent } \\
\text { workforce }\end{array}$ & $\begin{array}{l}\text { Accreditation of screening and } \\
\text { grading staff in accordance with } \\
\text { national standards }\end{array}$ & $\begin{array}{l}\text { All staff should be accredited for } \\
\text { their role within } 2 \text { years of } \\
\text { appointment }\end{array}$ & $\begin{array}{l}\text { Five graders had completed a } \\
\text { diabetic retinopathy grading course } \\
\text { recognised by the Association of } \\
\text { Optometrists Ireland, prior to the } \\
\text { initiative }\end{array}$ \\
\hline
\end{tabular}

eight public patients were already under the care of the ophthalmology service, while one patient was newly referred to the specialist service. The proposed national standards advise that patients with proliferative retinopathy be assessed by a consultant ophthalmologist within 2 weeks of referral. Of the eight patients referred to the public service, one patient was seen within the 2-week target, referred as an emergency on the day of screening; one was seen within 1 month; and three were seen within 3 months. Two patients were given an appointment over 5 months from the original referral date, and one was given an appointment over 12 months from the referral date.

According to the proposed national 
standards, patients with pre-proliferative retinopathy (R2) and maculopathy (M1) require consultation with a specialist within 13 weeks of referral: 109 patients in this study ( $7 \%$ of sample). Of these patients, 22 did not have a referral logged in the hospital system at the time of evaluation (20.1\%). Fifty-six patients requiring a consultation within 13 weeks were already under the care of a specialist (51.4\%), and a number of these patients had appointments prior to referral by the screening initiative.

Fifty-three patients were not previously under the care of an ophthalmology specialist (48.6\%). Of these newly referred patients, 17 did not have a referral logged in the hospital system (32.0\%) at the time of analysis. The mean waiting time for newly referred patients was 11 months (SD $=8.7$ months). Eight patients were seen within the 13-week target (15\%) (Figure 3).

\section{Quality assurance}

Table 1 presents the results of the screening initiative benchmarked against the proposed national quality standards set by the National Retinopathy Screening Committee. ${ }^{11}$ Overall, 30\% of images were sent for arbitrary grading $(n=462)$. Six per cent of images were deemed ungradable ( $n=99$ ), in line with the national minimum standard $(<10 \%)$.

\section{DISCUSSION \\ Summary}

Diabetic retinopathy screening provided through general practice, using existing skills and resources in the community, is both feasible and acceptable. Similar to the English model, screening was delivered locally by 15 community optometry clinics and two community ophthalmologists, in line with national quality standards and protocols. ${ }^{11}$ In accordance with those standards, $100 \%$ of all eligible patients with diabetes, within the DiGP scheme, were invited to participate. The invitation process and referrals to specialist services were coordinated by 30 general practices. Fortynine per cent of patients took up the offer of screening. Of those, $26 \%$ had some level of retinopathy detected, including 3\% with pre-proliferative retinopathy and $0.7 \%$ with proliferative retinopathy.

\section{Strengths and limitations}

This community-based screening initiative is aligned with the model of chronic care delivery within DiGP practices, whereby the routine management of type 2 diabetes takes place largely in general practice, although some patients also attend hospital-based specialist services for annual review and the management of complications. Patients with type 1 diabetes are managed by the hospital-based specialist services, and only those who do not attend the hospital are looked after in general practice.

This study was unable to compare the characteristics of those who did and did not attend for screening; however, the profile of those who attended is in line with the demographics of patients enrolled in DiGP practices; the majority have type 2 diabetes, over $50 \%$ are male, and the average age is 66 years. Although the uptake rate was below the national minimum standard of $70 \%$, the initiative had only been in operation for 6 months at the time of analysis and patients who had not attended were not issued with a reminder. Research suggests that multiple reminders have more of an impact than single reminders on the rate of retinal examinations among patients with diabetes. ${ }^{18}$ However, the improvement is only detected after the second reminder (at 3 months) and the value of multiple reminders has been questioned, given the additional resources required for a clinically small improvement in attendance.

Owing to the lack of integrated care, including adequate information and communication systems, it was not possible to determine how many of those who did not participate in the initiative received screening elsewhere, and therefore may not have needed to respond. In a populationbased screening programme, all patients need to be accounted for, including those who continue with their current provider (for example, hospital service) or choose to attend privately for screening. A national diabetes register should be established to facilitate an efficient recall system and to enable thorough and accurate follow-up of attenders and non-attenders.

\section{Comparison with existing literature}

In Scotland, where a second invitation is sent to non-attenders, the uptake rate over a 6-month period (43\%) was similar to that achieved in this study. ${ }^{19}$ Over the course of 12 months, $85 \%$ of the eligible population were screened in Scotland..$^{20}$ Similarly, recent results from the English National Screening Programme for Diabetic Retinopathy indicate an uptake rate of $79 \% .{ }^{21}$ Given that attendance at previous screening may be predictive of future uptake, ${ }^{22}$ it is important to improve the $49 \%$ attendance rate achieved by this initiative. A qualitative study of the factors influencing attendance at ophthalmic outpatient clinics in the UK found that a lack of awareness of the 


\section{Funding}

The Health Service Executive in Ireland funded the retinopathy screening initiative. Sheena Mc Hugh was funded by the Irish Health Research Board (HRB) as a PhD Scholar of the Health Services Research Institute.

\section{Ethical approval}

Ethical approval was obtained from the Clinical Research Ethics Committee for University College Cork (Reference ECM4 (dd) 05/04/11).

\section{Provenance}

Freely submitted; externally peer reviewed.

\section{Competing interests}

DiGP Ltd lof which Colin P Bradley, Claire Buckley, Joe Moran, and Diarmuid Quinlan are board members) has received financial support from Eli Lilly and Sanofi Aventis for the provision of education to general practice staff and has received financial support from Novo Nordisk, Sanofi Aventis and MSD for the employment a diabetes nurse specialist. Sue Doherty, Mark James, and John Traynor were reimbursed by the Health Service Executive for seeing patients referred from the screening initiative. The other authors have declared no competing interests.

\section{Acknowledgements}

We would like to thank the DiGP practices, optometry clinics, staff and patients who participated in the initiative.

\section{Discuss this article}

Contribute and read comments about this article on the Discussion Forum: http://www.rcgp.org.uk/bjgp-discuss severity of retinopathy was the main barrier to attendance. ${ }^{23} \mathrm{~A}$ lack of knowledge about the need for screening was also identified as a barrier to attendance in Ireland. ${ }^{24}$ As part of routine patient education, there is a need to create greater awareness of the importance of retinopathy screening as well as explicitly highlighting the risk of asymptomatic disease and the risks of blindness. ${ }^{23}$

The prevalence of retinopathy internationally varies widely, depending on methodology and the population sampled; however, the results of this study are in line with international estimates. The prevalence of retinopathy (any type) among people with diabetes in primary care in the UK was estimated to be $25 \%,{ }^{25}$ which is comparable to the results of this study. Furthermore, the Australian Diabetes, Obesity and Lifestyle study (AusDiab) found that pre-proliferative retinopathy was present in $2.1 \%$ of those with known type 2 diabetes, while proliferative retinopathy was present in $1.2 \%,{ }^{26}$ which is similar to the prevalence estimates in this study of $3 \%$ and $0.7 \%$ respectively.

\section{Implications for research and practice}

The detection of sight-threatening retinopathy among 11 patients in this study is worrying, given that retinopathy screening is an internationally recognised standard of diabetes care. Further research is needed to examine the clinical management of patients with all levels of retinopathy, including an assessment of the quality of vascular risk control and the current treatment provided in the general practice setting.

Eight of the patients with sightthreatening retinopathy were already under the care of the specialist service, with a further three seeking care privately. However, three of the 11 patients with sight-threatening retinopathy were given appointments for the specialist service that were over 5 months from the original referral date. The delays in patients being seen following screening is a real barrier to the effectiveness of population screening and will have serious implications for the provision of screening for diabetic retinopathy on a national scale. According to the proposed national standards, patients with pre-proliferative retinopathy and maculopathy require consultation with a specialist within 13 weeks of notification of a positive test. ${ }^{11}$ In this study, approximately half of these patients were not previously under the care of a specialist within the ophthalmology service, despite having pre-proliferative retinopathy or maculopathy. Almost onethird of these 'new' patients did not have a referral logged in the hospital system. The most likely explanation is that patients chose to attend private services and therefore were not recorded in the public health system database. In the absence of a unique patient identifier in the Irish health system, it is not possible to track patients across settings and providers. Of those who were not under the care of a specialist, almost $25 \%$ had to wait longer than 12 months for a consultation. Only 15\% of 'new' patients were seen within the 13-week target. The number of new undiagnosed patients introduced to the system is very small and therefore should be manageable within the current ophthalmology service. However, the results highlight the need for a clear referral and communication pathway between primary, secondary, and tertiary care, to ensure that all patients are treated in a timely manner.

This study has shown that the community-based model is acceptable and accessible and can provide qualityassured screening to patients with diabetes. The initiative was both timely and necessary, in the absence of a population-based screening programme, and significant learning can be derived from its implementation, particularly the challenges and blockages identified that were due to the lack of integrated care in the system. The community-based model represents a practical and viable example of the reconfiguration of chronic disease management from the acute setting to the community, as it utilised existing infrastructure, skills, and services. This shift from acute reactive care to planned systematic services had been advocated in several national policy documents. ${ }^{27-30}$ Given that approximately $25 \%$ of those screened had some level of retinopathy, the results of this initiative highlight the need for a national screening programme in Ireland. 


\section{REFERENCES}

1. Jönsson B. Revealing the cost of type II diabetes in Europe. Diabetologia 2002 45(7): $5-12$.

2. Williams R, Van Gaal L, Lucioni C. Assessing the impact of complications on the costs of Type II diabetes. Diabetologia 2002; 45(7): 13-17.

3. Ockrim Z, Yorston D. Managing diabetic retinopathy. BMJ 2010, 341: c5400.

4. Ghafour IM, Allan D, Foulds WS. Common causes of blindness and visual handicap in the west of Scotland. Br J Ophthalmol 1983; 67(4): 209-213.

5. Congdon NG, Friedman DS, Lietman T. Important causes of visual impairment in the world today. JAMA 2003; 290(15): 2057-2060.

6. Bunce $C$, Xing W, Wormald R. Causes of blind and partial sight certifications in England and Wales: April 2007-March 2008. Eye 2010; 24(11): 1692-1699.

7. Kelliher C, Kenny D, O'Brien C. Trends in blind registration in the adult population of the Republic of Ireland 1996-2003. Br J Ophthalmol 2006; 90(3): 367.

8. National Institute for Health and Clinical Excellence. Type 2 diabetes: management of type 2 diabetes. Clinical guidelines CG66. London: NICE, 2008.

9. Scottish Intercollegiate Guidelines Network. Management of diabetes. A national clinical guideline. Edinburgh: Scottish Intercollegiate Guidelines Network, 2010.

10. American Diabetes Association. Diabetic retinopathy. Diabetes Care 2002, 25(suppl 1): s90-s93.

11. Expert Advisory Group National Retinopathy Screening Committee. Framework for the development of a diabetic retinopathy screening programme for Ireland. Naas: Health Service Executive, 2008

12. Screening for diabetic retinopathy in Europe 15 years after the St Vincent Declaration. The Liverpool Declaration 2005. Report of conference 17-18 November 2005. http://reseau-ophdiat.aphp.fr/Document/Doc/confliverpool.pdf laccessed 18 Dec 2012).

13. Department Of Health. National Service Framework for Diabetes: standards. London: Department of Health, 2001.

14. Younis N, Broadbent D, James M, et al. Current status of screening for diabetic retinopathy in the UK. Diabet Med 2002; 19(suppl 4): 44-49.

15. Mc Hugh S, O'Keeffe J, Fitzpatrick A, et al. Diabetes care in Ireland: a survey of general practitioners. Prim Care Diabetes 2009; 3(4): 225-231.

16. Aldington S, Kohner E, Meuer S, et al. Methodology for retinal photography and assessment of diabetic retinopathy: the EURODIAB IDDM complications study. Diabetologia 1995; 38(4): 437-444.
17. UK National Screening Committee. Essential elements in developing a diabetic retinopathy screening programme. London: UK National Screening Committee 2007.

18. Halbert RJ, Leung KM, Nichol JM, Legorreta AP. Effect of multiple patient reminders in improving diabetic retinopathy screening. A randomized trial. Diabetes Care 1999; 22(5): 752.

19. Scottish Diabetic Retinopathy Screening Collaborative. Interim report October 2010. http://www.ndrs.scot.nhs.uk/Templates/Docs/DRS\%20Collaborative\%20 Interim\%20report\%202010-11\%20Final.pdf (accessed 6 Dec 2012).

20. NHS Scotland. National Diabetes Retinopathy Screening. Screening progress for Q4 - FY 2011. [Snap shot of the status taken on 31 March 2011] http://uww.ndrs. scot.nhs.uk/ laccessed 6 Dec 2012).

21. UK National Screening Committee. Annual report. English National Screening Programme for Diabetic Retinopathy April 2010-March 2011. Gloucester: English National Screening Programme for Diabetic Retinopathy, 2011.

22. Jepson R, Clegg A, Forbes C, et al. The determinants of screening uptake and interventions for increasing uptake: a systematic review. Health Technol Assess 2000; 4(14): i

23. Lewis K, Patel D, Yorston D, Charteris D. A qualitative study in the United Kingdom of factors influencing attendance by patients with diabetes at ophthalmic outpatient clinics. Ophthalmic Epidemiol 2007; 14(6): 375-380.

24. Dervan E, Lillis D, Flynn L, et al. Factors that influence the patient uptake of diabetic retinopathy screening. Ir J Med Sci 2008; 177(4): 303-308.

25. Younis N, Broadbent D, Harding S, Vora J. Prevalence of diabetic eye disease in patients entering a systematic primary care based eye screening programme. Diabet Med 2002; 19(12): 1014-1021.

26. Tapp RJ, Shaw JE, Harper CA, et al. The prevalence of and factors associated with diabetic retinopathy in the Australian population. Diabet Care 2003; 26(6): 1731-1737

27. Department of Health and Children. Diabetes: prevention and model for patient care. Dublin: Department of Health and Children, 2006.

28. Clarke A, Diabetes Service Development Group. Diabetes care: securing the future. Report of the Diabetes Service Development Group. Dublin: Diabetes Service Development Group, 2002.

29. Expert Advisory Group for Diabetes. Diabetes Expert Advisory Group first report April 2008. Dublin: Health Service Executive, 2008.

30. Department of Health and Children. Tackling chronic disease. A policy framework for the management of chronic disease. Dublin: Department of Health and Children, 2008. 